\title{
Influence of provision of concentrate at milking on voluntary cow traffic in a pasture-based automatic milking system
}

\author{
V. E. Scott, ${ }^{* 1}$ P. C. Thomson, † K. L. Kerrisk, ${ }^{*}$ and S. C. Garcia* \\ *Dairy Science Group, Faculty of Veterinary Science, The University of Sydney, Camden, NSW 2570, Australia \\ †ReproGen - Animal Bioscience Group, Faculty of Veterinary Science, The University of Sydney, Camden, NSW 2570, Australia
}

\begin{abstract}
The success of an automatic milking system is generally reliant upon the voluntary movement of cows around the farm system and the correct management of incentives to achieve a targeted level of cow traffic. The present study investigated the effect of providing a small feed reward as an incentive at milking on the premilking voluntary waiting time of cows milked on a prototype robotic rotary in an Australian pasture-based dairy. The 2 treatments were "feed on" (concentrate offered at milking) and "feed off" (no concentrate offered at milking), with data from a single herd of 168 lactating dairy cows collected over $16 \mathrm{~d}$. A survival analysis with time-varying covariates was used to model the voluntary waiting times of cows in the premilking yard. The median time cows spent waiting before milking was 129 min and after $4 \mathrm{~h}$ just over $70 \%$ of the cows had exited the yard (volunteered for milking). When feed was provided, cows were faster to exit the premilking yard (shorter time spent waiting) and waited just over half the time $(0.53 \times)$ they did during the "feed off" treatment. Heifers exited the premilking yard more rapidly than cows in later lactations, with older cows spending at least 1.40 times longer in the yard before milking. Average daily milk yield along with stage of lactation and fetching cows from the paddock also influenced cow traffic in the premilking yard. As the number of cows in the premilking yard increased, voluntary waiting time also increased. At a queue length of 20 or more cows, the negative effect on waiting time of an additional cow entering the yard was less than that when fewer than 20 cows were present. Results demonstrated that feeding a small reward on the robotic rotary platform can reduce the time cows spend in the premilking yard, leading to a potential reduction in the risk of congestion at the dairy, particularly during times of high demand. Minimizing congestion will likely benefit multiple aspects of the voluntary milking operation, including a
\end{abstract}

Received August 15, 2013.

Accepted November 27, 2013.

${ }^{1}$ Corresponding author: tori.scott@sydney.edu.au potential improvement in robot utilization, a reduction in unnecessary time spent off pasture by cows in the milking herd, promoting cow welfare through reducing the risk of lameness, and enhancing productivity. Targeting strategies to minimize queue length to less than the threshold length, which in this study was 20 cows, could result in reduced time spent in the premilking yard.

Key words: automatic milking, feed incentive, robotic rotary, waiting time

\section{INTRODUCTION}

Automatic milking systems (AMS) have been designed to accommodate milkings distributed across the entire day and night, with reported benefits including reduced labor inputs at milk harvesting and improved lifestyle (Rossing et al., 1997; Rotz, 2003; Mathijs, 2004; Bijl et al., 2007). The potential to capture the greatest benefits of AMS is achievable with voluntary cow traffic, an incentive-based management strategy whereby cows set their own daily routine and traffic around the system to achieve milkings with little or no human intervention. In addition, operating AMS may also alter milking frequency (MF; the number of times an individual cow is milked per day) and potentially milk yield compared with conventional systems (Wagner-Storch and Palmer, 2003; de Koning and Rodenburg, 2004), without increasing labor. However, the target MF will be dependent on the system type and production level of the cows. For example, in a pasture-based system reliant on minimizing the cost of production to remain profitable, a balance between increased production per cow (e.g., through increased MF or increased feeding level, or both) and increased volumes of milk harvested per milking unit (e.g., increased number of cows milked per milking unit) should be carefully considered (Jago and Burke, 2010).

Social order plays a strong role in determining an individual animal's access to a resource (Blanckenhorn and Caraco, 1992; Kokko and Johnstone, 1999), and in competitive situations, it is not uncommon for an animal to wait for an opportunity to access a resource. 
Similarly in AMS, social order can influence access to the robotic milking unit, where cows of lower social status have been shown to wait longer in front of the robotic milking unit (Lexer et al., 2009) and spend more time in the waiting area (Melin et al., 2006) than cows of higher social status. Long premilking waiting times may negatively affect cow time budgets and production and, in extreme cases, also create welfare concerns, such as the development of lameness. It is, therefore, necessary to minimize the time cows voluntarily spend waiting at the robotic unit, both from a system and an animal welfare aspect.

It is widely acknowledged that AMS can be successfully combined with pasture-based dairying operations (Ketelaar-de Lauwere and Ipema, 2000; Jago et al., 2002; Jago and Kerrisk, 2011), such as those in Australia and New Zealand. In these systems, large herds (exceeding several hundred cows) are common. With the development of high-throughput technology [robotic rotary (RR); Automatic Milking Rotary; DeLaval International AB, Tumba, Sweden] estimated to be capable of performing up to 1,600 milkings per day (Kolbach et al., 2012) and, therefore, suited to larger herds, it is pertinent that the risk of congestion, competition, and subsequent inefficiencies in cow traffic at the dairy are minimized, particularly during times of greatest demand. Improved knowledge around the provision and management of incentives will be important if efficient systems with high levels of productivity are to be achieved.

Numerous incentives to encourage voluntary cow traffic have been investigated in pasture-based systems, including supplementary feeding strategies (Jago et al., 2007; Lyons et al., 2013b), pasture allocation (Lyons et al., 2013a), and the use of water availability and locality (Jago et al., 2003). Jago et al. (2007) reported an increase in the number of visits to a premilking selection gate when fresh feed allocations became available, and Lyons et al. (2013a) described how the number of milkings per cow per day and daily milk yield increased when cows were offered 3 fresh pasture allocations per day compared with 2 allocations. Feeding to improve cow traffic throughout the farm in indoor-housed systems is also well documented (Prescott et al., 1998a; Halachmi et al., 2005; Bach et al., 2007). Furthermore, when simultaneously offered the choice between feeding and milking, it has been shown that cows will more often choose feeding over milking (Prescott et al., 1998b). As such, feed is considered to be one of the most effective incentives for increasing voluntary cow traffic in AMS.

In single-box AMS, feed is dispensed through a feeding trough, and individual cow intake at each milking can be recorded. However, at present, in-bail feeding is not an integrated function of the RR and cows milked on an $\mathrm{RR}$ are required to present for milking without a direct feed reward. In small herd sizes, feeding at milking in single-box AMS does not always result in increased MF (Prescott et al., 1998a; Jago et al., 2004), although it was recognized by Jago et al. (2004) that a small proportion of cows not allocated feed had access to left-over feed at milking. In this case, results could have been affected by non-fed cows trafficking as a response to expecting feed rather than actually receiving feed. Furthermore, cows milked on an RR may behave differently or be subject to altered social dynamics (e.g., greater potential for dominance and competition) than cows in herds of similar size milked in single-box AMS due to the RR having a single-entry point rather than multiple-entry points in systems with more than 1 single-box robot. When coupled with a high-throughput capacity and, therefore, large herd size, efficient cow traffic onto the RR is potentially even more critical than in single-box systems and research into developing successful and reliable management practices to encourage cow traffic is required in the $R R$ system.

The primary objective of the present study was to investigate the effect of offering a small amount of pelleted concentrate on premilking voluntary waiting times of cows managed in a pasture-based AMS and milked on a prototype RR, with no possibility of non-fed cows accessing any concentrate at milking. It was hypothesized that the provision of a feed reward at milking would result in cows spending less time in the premilking yard. A secondary objective was to determine factors that affect premilking waiting times in an RR system to increase understanding and allow for future development of strategic management decisions for cows with prolonged waiting times.

\section{MATERIALS AND METHODS}

\section{Animal and Feed Management}

Research was conducted at the FutureDairy AMS research farm (Elizabeth Macarthur Agricultural Institute, New South Wales Department of Primary Industries, Camden, New South Wales, Australia). Ethics approval was granted through the Elizabeth Macarthur Agricultural Institute Animal Ethics Committee (project number M10/12) before the commencement of this project.

During the study, 168 mixed-breed (Holstein-Friesian, Holstein $\times$ Illawarra, and Illawarra) dairy cows were managed as a single voluntary trafficking herd. Cows were milked on a prototype 16-bail internal herringbone RR (Kolbach et al., 2012) in a pasture-based 
Table 1. Description of milking permission criteria

\begin{tabular}{lll}
\hline Item & $<70$ DIM & $>70 \mathrm{DIM}$ \\
\hline Primiparous animals & $4 \mathrm{~h}$ & $8 \mathrm{~h}$ \\
Multiparous animals & Expected yield $>4 \mathrm{~L}$ & Expected yield $>4.5 \mathrm{~L}$ \\
& $4 \mathrm{~h}$ & $8 \mathrm{~h}$ \\
& Expected yield $>6.5 \mathrm{~L}$ & Expected yield $>6.5 \mathrm{~L}$ \\
\hline
\end{tabular}

system. The herd consisted of $30 \%$ primiparous and $70 \%$ multiparous cows, averaging 3 lactations (median $=2 ; \mathrm{SD}=2.1$ ). Prior to the commencement of the study, the 7-d average milk yield for the herd was 18.5 $\mathrm{L} /$ cow per day $($ median $=17.8 \mathrm{~L} ; \mathrm{SD}=6.3 \mathrm{~L})$, with an average MF of 1.7 milkings/cow per day (median $=2 ; \mathrm{SD}=0.4$ ). Cows had up to 18 mo intermittent exposure on the RR and had been milked exclusively on the RR under voluntary traffic conditions for $6 \mathrm{wk}$ before the commencement of the study.

Pasture was managed under a 2-way grazing strategy (Kerrisk, 2009; Lyons et al., 2013a); 2 pasture allocations were made available to the herd during each 24 -h period (day and night allocations from 0830 to $1800 \mathrm{~h}$ and 1800 to $0830 \mathrm{~h}$, respectively), with pasture species predominantly a mix of Kikuyu (Pennisetum clandestinum) and ryegrass (Lolium perenne). A total of $20 \mathrm{~kg}$ of $\mathrm{DM} /$ cow per day was allocated to the herd, consisting of pasture $(7 \mathrm{~kg}$ of $\mathrm{DM} / \mathrm{cow}$ allocated in each of the day and night pasture allocations) and partial mixed ration (PMR; $6 \mathrm{~kg}$ of $\mathrm{DM} / \mathrm{cow}$ per day). The PMR consisted of (\% of dry weight) $62 \%$ maize silage, $21 \%$ pelleted concentrate ( $18 \%$ protein), $8.5 \%$ oaten hay, $7.3 \%$ lucerne silage, and $1.2 \%$ oaten silage. Water was available ad libitum in the paddocks and at the dairy postmilking.

\section{Farm and RR Management}

The RR operated $24 \mathrm{~h}$ per day. Milking was separated into day and night voluntary sessions, beginning at approximately 0830 and $1900 \mathrm{~h}$, respectively, and concluding with the commencement of batch milking of abnormal milk cows (colostrum, antibiotics, and mastitis) and a full system wash at approximately 1800 and $0700 \mathrm{~h}$, respectively. Voluntary access was denied to the herd during these activities, thereby limiting voluntary access periods to a total of approximately $21.5 \mathrm{~h} / \mathrm{d}$.

To maintain high-quality bulk milk, any bail that remained idle for more than $1 \mathrm{~h}$ after its last milking was automatically deactivated. To better match the herd size with the throughput potential of the equipment, only half of the available bails ( 8 out of 16 ) were activated at the start of each milking session. Bails were activated in 1 of 4 predetermined sequences, being (1) 8 consecutive bails activated, (2) 2 lots of 4 consecu- tive bails activated, (3) 4 lots of 2 consecutive bails activated, and (4) every other bail activated [detailed description in Kolbach et al. (2013)]. An additional 4 bails were activated at 1100 and $1400 \mathrm{~h}$ during the day milking session and at 2300 and $0200 \mathrm{~h}$ during the night milking session to maintain active bails throughout each milking session.

Milking permission (automatically drafting a cow into the dairy to be milked) was granted on an individual-cow basis, dependent on the time that had elapsed since the last milking, the expected milk yield, DIM, and parity (Table 1), with a minimum milking interval (MI) of $4 \mathrm{~h}$. For example, a primiparous cow milked more than $4 \mathrm{~h}$ previous and expected to produce more than $4 \mathrm{~L}$ was granted access to the $\mathrm{RR}$ if she was $<70$ DIM. Cows without milking permission were drafted back to pasture.

Following a successful milking, cows were directed to PMR on a postmilking feed pad before exiting the dairy. Incompletely milked cows (i.e., an unsuccessful milking attempt due to failed attachment or premature milking cup removal) were drafted into a separate area with access to PMR and water, and were manually milked on the RR before milking abnormal-milk cows during the day milking session. During the night session, cows were automatically drafted back to the RR for a second milking attempt.

\section{Experimental Design}

The experiment was conducted over a 35 -d period throughout March and April 2011. Data were collected over $16 \mathrm{~d}$. To determine the effect of offering feed at milking on the RR on cow traffic in the dairy, a small amount of pelleted concentrate (approximately $300 \mathrm{~g} /$ cow per milking; $18 \%$ protein) was offered for half of the study period, with treatments being "feed on" (concentrate offered at milking) and "feed off" (no concentrate offered at milking). Feed was offered in fixed, custom-built metal bins located at the first 2 entry bails of the RR platform (Kolbach et al., 2013), although it was not possible to measure consumption per cow or whether a cow refused the feed on offer. If a cow refused the feed on offer, the refused feed along with a new allocation of feed were available to the subsequent cow. 
Table 2. Trial design and treatment allocation, including data collection and habituation days

\begin{tabular}{lclc}
\hline Treatment $^{1}$ & Period & Activity & Duration $(\mathrm{d})$ \\
\hline Feed on & 1 & Habituation & 2 \\
\multirow{2}{*}{ Feed off } & \multirow{2}{*}{2} & Data collection & 3 \\
& & Settling & 7 \\
& & Habituation & 5 \\
Feed off & \multirow{2}{*}{3} & Data collection & 4 \\
& \multirow{2}{*}{ Feed on } & No data collected & 3 \\
& \multirow{2}{*}{4} & Data collection & 4 \\
& & Habituation & 2 \\
\hline
\end{tabular}

"Feed on" = concentrate offered at milking; "feed off" = no concentrate offered at milking.

${ }^{2}$ Given following technical failure to ensure that voluntary, distributed cow traffic had resumed.

${ }^{3}$ Data were not collected due to insufficient labor availability.

${ }^{4}$ Data collection included an additional day from period 1 .

Data collection days were as follows: a 3 -d period of "feed on," two 4-d periods of "feed off," and a 5-d period of "feed on" (Table 2). Each period was designed to last for $4 \mathrm{~d}$ total. The first period of "feed on" was prematurely terminated due to a technological failure (a breakdown) and the missing treatment day was applied to the final "feed on" period. Following the breakdown, time was given $(7 \mathrm{~d})$ to allow voluntary, distributed cow traffic to settle before commencement of subsequent habituation and data collection periods. Limitations in infrastructure and an inability to selectively supply feed to some cows and deny it to others meant that the more ideal crossover design (where both treatments were applied simultaneously to groups within the herd) was not practical in this study; however, it was ensured that each cow was offered the correct treatment at each milking.

A period of habituation was provided following each change in treatment to allow cows to adjust to the feed treatment (Table 2). Cows were accustomed to being offered feed at milking, and so an extended habituation period following feed removal was implemented to allow for adjustment to an unfamiliar feeding strategy, whereas $2 \mathrm{~d}$ was deemed satisfactory when feed was resumed (based on previous experiences at the test site with cow traffic settling rapidly when feeding resumed after an interruption in supply).

Total waiting time was recorded as the time from entry into the premilking yard (area: $118.6 \mathrm{~m}^{2}$ ) until the cow presented for milking on the RR. Data were recorded electronically for every cow milking event using the management program VMS Client (DeLaval International $\mathrm{AB}$ ). Voluntary waiting time was calculated as the total time a cow was present in the premilking yard and could freely exit the yard by entering the $\mathrm{RR}$, excluding forced waiting time. Forced waiting time was considered to be when a cow was queuing in the premilking yard but was physically prevented from milking due to the following activities: machine downtime due to plant washing, milking of abnormal-milk or previously incompletely milked cows, maintenance, and breakdown. Forced waiting times were recorded to account for periods where voluntary milking was prevented.

Cows that had not returned to the dairy from the previous day or night paddock allocation were recorded daily and fetched to the dairy at approximately 0800 and $1730 \mathrm{~h}$, respectively. Prior to the end of a milking session, any cow $(\mathrm{s})$ remaining in the premilking yard were recorded and encouraged onto the RR platform. These management practices were carried out to reduce the risk of any MI (time between 2 consecutive milkings) exceeding $24 \mathrm{~h}$ and ensured that cows could spend no more than approximately $11 \mathrm{~h}$ in the premilking yard during any 1 visit.

\section{Statistical Analysis}

Lactation number was grouped into 4 classes of similar size, with classes 1 to 3 representing their corresponding lactation number and class $4+$ representing lactations 4 and above. Milk production (yield) per cow was determined through averaging daily milk yield throughout the study. For each cow, DIM was calculated as the number of days from calving to the trial start date. Prior to analysis, cows that began the study with less than $14 \mathrm{~d}$ experience on the RR (DIM $<14)$ were excluded $(n=22)$ from the data set $(204$ milkings). Milkings from abnormal-milk cows were also removed from the data set (492 milkings). Altogether, 696 milkings $(19.2 \%)$ were discarded.

To analyze the data, a Cox proportional hazards regression analysis with time-varying covariates (number of cows in the premilking yard) was used to model voluntary waiting times (Hosmer et al., 2008), with the voluntary waiting time considered as the survival time. The analysis was conducted using the $\operatorname{coxph}()$ function in the survival package of $\mathrm{R}$ (R Core Team, 2013). Voluntary waiting times that concluded with a cow being encouraged onto the RR platform were included in the analysis as censored data (total time spent in the premilking yard was unknown, but exceeded the time at censoring). Similarly, any voluntary waiting times that had a portion of time as forced were also included as censored data. Note that a Cox proportional hazards model considers explanatory variables that affect the hazard of an event happening, the event here being the cow exiting the premilking yard and, consequently, terms that are associated with increased hazard indicate that the cows spent a reduced amount of time in the premilking yard. 
Allowance was made for multiple observations on each animal, as well as multiple observations on any trial day, through the use of cluster terms. Incorporating time-varying covariates enabled the inclusion of a data record whenever the covariate (number of cows in the premilking yard) changed for each animal for the period of time present in the premilking yard, totaling more than 51,000 records. Penalized splines [given as $s(\cdot)$ in the model below] were used, enabling the nature of any nonlinear trends to be specified by the data rather than imposing linear trends or placing data into categories with consequent loss of information.

The following model was fitted to the data:

$$
\begin{gathered}
\log _{e} h(t ; \mathbf{x})=\log _{e} h_{0}(t)+\text { Treat }+ \text { DayNight }+ \text { LacNo } \\
+s(\text { DIM })+s(\text { Yield })+\text { Fet }+s(\text { NCow }) \\
+ \text { BailActiv }+s(\text { Pasture })+\text { CowID }+ \text { TrialDay }
\end{gathered}
$$

where $\log _{e} h(t ; \mathbf{x})$ is the log of the hazard of a cow exiting the premilking yard ( $t=$ the voluntary waiting time), given the explanatory variables $\mathbf{x}$, and $\log _{e} h_{0}(t)$ is the log of the baseline hazard (the hazard when all explanatory variables are kept at their mean). The explanatory variables (fixed effects) included Treat (the effect of feed treatment; "feed on" or "feed off"), DayNight (the time of day of an event, being 0700 to $1900 \mathrm{~h}$ and 1900 to $0700 \mathrm{~h}$ for day and night, respectively), LacNo (the lactation group: 1, 2, 3, or 4+), DIM (the DIM at the commencement of the study), Yield (the average daily yield per cow across the study duration), Fet (whether the cow arrived at the dairy as a result of being fetched from the paddock, as yes or no), NCow (the number of cows in the premilking yard at the arrival of each new cow), BailActiv (the bail activation sequence at commencement of a new milking session), and Pasture (the daily allowance of pasture averaged per cow). Random effects were CowID (individual cow, identified by a unique number) and TrialDay (a 24-h data collection day, with a new trial day beginning at the start of the day milking session and concluding at the end of the night milking session), both specified as cluster terms in the model.

From the fitted model, hazard ratios $>1$ indicate a higher hazard of exiting the premilking yard (i.e., shorter time spent in the premilking yard before milking) compared with the reference level for each categorical explanatory variable, whereas hazard ratios $<1$ indicate a lower hazard of exiting (i.e., longer time spent in the premilking yard before milking). Note that the use of the term hazard in survival analysis does not necessarily imply a deleterious outcome and, in this study, the hazard refers to the voluntary movement from the premilking yard to the RR platform.

\section{RESULTS}

A total of 2,935 milkings were analyzed $(\mathrm{n}=1,649$ and $\mathrm{n}=1,286$ for "feed on" and "feed off" treatments, respectively). Summary statistics of the mean milk production, MF, and MI for each treatment are presented in Table 3.

A Kaplan-Meier baseline survival curve for the proportion of cows remaining in the premilking yard as time progressed was used to evaluate survival times (Figure 1). The median voluntary waiting time was 129 min when all covariates and factor levels were held at their average. The median was used because it provided a more accurate indication of the voluntary waiting time than the mean due to the presence of censored data. It was predicted that after a voluntary waiting time of $30 \mathrm{~min}, 17 \%$ of cows would have exited the premilking yard. This increased to $30 \%$ at $60 \mathrm{~min}$, and after $4 \mathrm{~h}$, it was estimated that just over $70 \%$ of the cows had exited the premilking yard.

\section{Feed Treatment}

Offering a small quantity of feed at milking resulted in a change in premilking voluntary waiting times $(P$ $<0.001)$. During the treatment "feed on," cows had an almost 2-fold greater hazard of volunteering onto

Table 3. Summary statistics for milk yield, milking frequency, and milking interval between treatment periods ( $P$-values obtained from a paired $t$-test)

\begin{tabular}{llrrrc}
\hline Production factor & Treatment $^{1}$ & Mean & Median & SD & $P$-value \\
\hline Yield per milking (L) & Feed on & 10.6 & 9.9 & 3.6 & $<0.05$ \\
& Feed off & 11.7 & 11.6 & 3.4 & \\
Daily yield (L) & Feed on & 18.5 & 18.5 & 5.9 & $<0.05$ \\
Milking frequency (milkings/cow per day) & Feed off & 16.5 & 15.6 & 5.6 & \\
& Feed on & 1.5 & 1.5 & 0.3 & $<0.05$ \\
Milking interval (h) & Feed off & 1.3 & 1.3 & 0.2 & \\
& Feed on & 15.7 & 14.9 & 4.6 & $<0.05$ \\
\hline
\end{tabular}

"Feed on" = concentrate offered at milking; "feed off" = no concentrate offered at milking. 


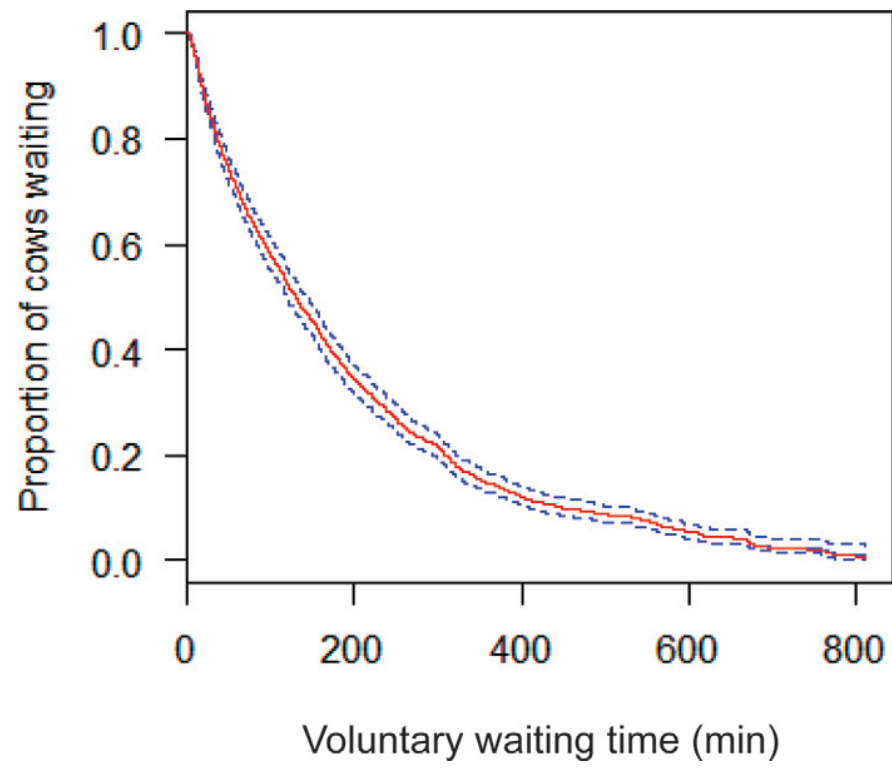

Figure 1. Baseline survival curve (solid line = survival curve; broken lines $= \pm \mathrm{SE}$ ) representing the change in the proportion of cows present in the premilking yard as a function of time, where 0 is the time of entry into the premilking yard. Color version available in the online PDF.

the RR platform from the premilking yard, spending almost half $(0.53 \times)$ the time in the premilking yard, compared with when feed was not offered (Table 4).

\section{Cow Traits and Management Factors}

Lactation had an effect on premilking voluntary waiting time $(P<0.001$; Table 4$)$. All lactation groups were found to have a lower hazard ratio than the reference level group (first-lactation heifers), indicating that heifers spent the least amount of time waiting before milking. As lactation group increased, the time spent in the premilking yard tended to increase. Cows in lactation group $4+$ had a 1.99-fold increase in voluntary waiting time compared with heifers, whereas lactation groups 2 and 3 were similar, with an increased waiting time at just under 1.50 times that of heifers (Table 4).

Fetching cows from the paddock before milking increased the time spent in the premilking yard compared with cows that voluntarily returned to the dairy $(P<$ 0.001; Table 4). Cows that were fetched had a lower hazard ratio, and spent 1.56 times longer in the premilking yard before volunteering for milking than cows that were not fetched.

As lactation progressed, the hazard value increased $(P<0.001 ;$ Figure 2a), although this increase was not linear. Interestingly, cows early in lactation $(<100$ DIM) were found to have the smallest hazard value, indicating they waited the longest before volunteering for milking, whereas the hazard increased rapidly in late lactation (>200 DIM) and suggested that cows in late lactation spent the shortest time waiting before being milked. Further investigation (results not presented here) indicated that there was an approximately uniform distribution of cows from all stages of lactation present in the yard across time. A similar nonlinear effect was seen with average daily milk production $(P$ $<0.001$ ), where the hazard of exiting the premilking yard increased with increasing milk yield (Figure 2b); cows with high daily milk yields spent less time waiting before milking than cows with lower daily milk yields.

\section{Queue Length}

The statistical method chosen enabled the effect of the time-varying covariate of queue length (number of cows in the premilking yard) to be modeled (Figure 3). The hazard of exiting the premilking yard was affected by the number of cows present in the yard $(P<0.001)$, where the hazard decreased as the queue lengthened (cows spent more time waiting when more cows were present). Interestingly, a clear change in the rate of

Table 4. Hazard ratio of cows exiting the premilking yard and their 95\% CI (in parentheses) for the explanatory variables factors of treatment, lactation, and fetching

\begin{tabular}{llccccc}
\hline Variable & Group $^{1}$ & Coeff. $^{2}$ & SE (coeff.) & Hazard ratio & Time in yard $^{3}$ & $P$-value \\
\hline Treatment & Feed off & Ref. $^{4}$ & & & & \\
& Feed on & 0.64 & 0.07 & $1.89(1.65-2.15)$ & $0.53 \times$ & $2.2 \times 10^{-16}$ \\
Lactation & 1 & Ref. & & & & \\
& 2 & -0.36 & 0.14 & $0.70(0.54-0.92)$ & $1.43 \times$ & $<2.2 \times 10^{-16}$ \\
& 3 & -0.39 & 0.15 & $0.68(0.51-0.90)$ & $1.47 \times$ & \\
\multirow{2}{*}{ Fetched } & $4+$ & -0.69 & 0.14 & $0.50(0.38-0.66)$ & $1.99 \times$ & $1.6 \times 10^{-11}$ \\
& No & Ref. & & & & \\
& Yes & -0.44 & 0.07 & $0.64(0.56-0.74)$ & $1.56 \times$ & \\
\hline
\end{tabular}

"Feed on" = concentrate offered at milking; "feed off" = no concentrate offered at milking.

${ }^{2}$ Regression coefficient from the proportional hazards model.

${ }^{3}$ Calculated 1 /hazard ratio (i.e., average time spent waiting compared with the reference level).

${ }^{4}$ Ref. $=$ reference level. 
a)

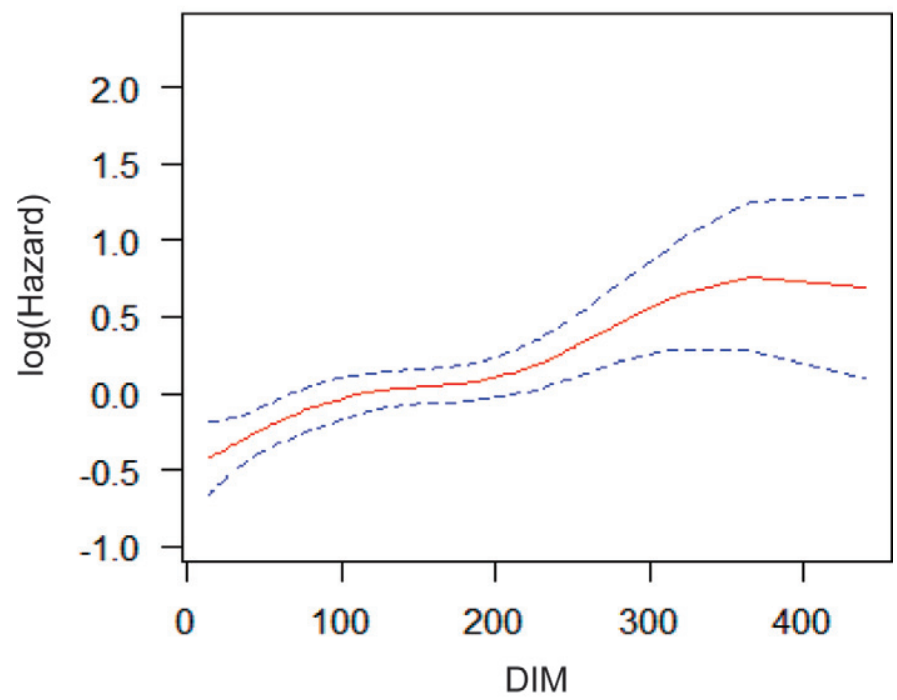

b)

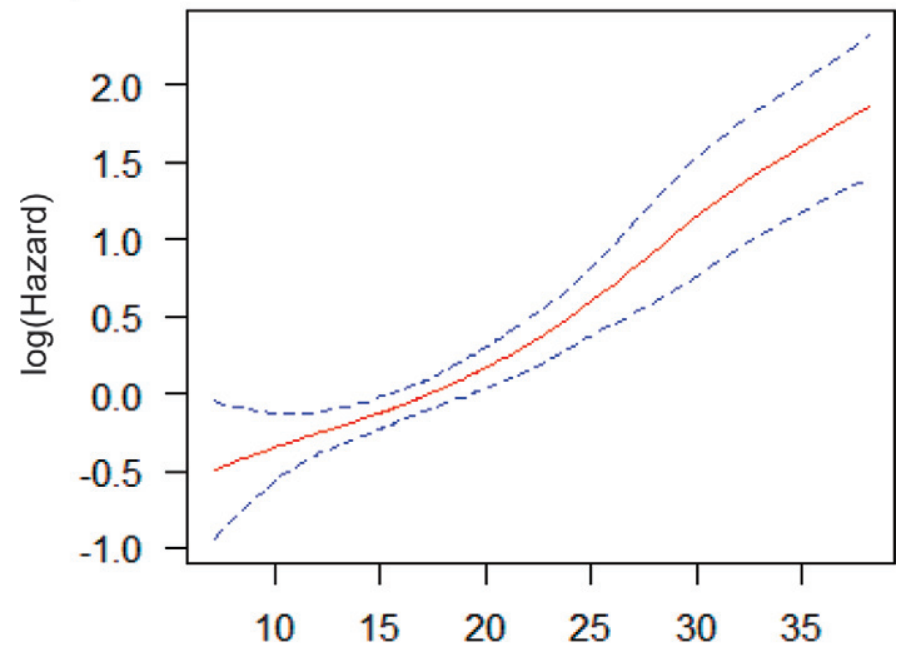

Average milk production (L/cow per day)

Figure 2. Spline function of the $\log$ hazard (solid line $=$ the $\log$ hazard; broken lines $= \pm \mathrm{SE}$ ) of exiting the premilking yard for covariate explanatory variables of (a) DIM and (b) average daily milk production. All other explanatory variables were held at their averages. Color version available in the online PDF.

decline of the hazard can be seen at approximately 20 cows, indicating that, for this AMS configuration, the change in hazard for every 1 additional cow in the yard after 20 cows were already present had a reduced effect in decreasing the hazard than the addition of a single cow to the queue when less than 20 cows were present. Descriptive statistics indicated that a queue length of less than 20 cows occurred 27 and $5 \%$ of the time, with a median queue length of 28 cows and 49 cows, for treatments "feed on" and "feed off," respectively.



Figure 3. Spline function of the log hazard (solid line $=$ the $\log$ hazard; broken lines $= \pm \mathrm{SE}$ ) of exiting the premilking yard as the cow queue length changed (time-varying covariate). All other explanatory variables were held at their averages. Color version available in the online PDF.

\section{Other Factors}

Pasture allocation, bail activation sequence, and time of day (day or night) did not significantly affect voluntary waiting time $(P=0.06, P=0.06$, and $P=0.07$, respectively). These explanatory variables will not be discussed further in this paper.

\section{DISCUSSION}

Offering a small feed reward upon entry onto an RR reduced the voluntary waiting time of cows in the premilking yard, as hypothesized, and may be a viable management strategy to encourage cows queuing in the premilking yard to volunteer for milking. Furthermore, the strong (almost 2-fold increase in cow traffic) response to feed suggests that feeding was successful in reducing voluntary waiting time, regardless of cows previously being accustomed to receiving feed at milking. Previous studies have also demonstrated feed to be a strong incentive for encouraging cow traffic in AMS (Prescott et al., 1998a; Lyons et al., 2013b) and simulated AMS scenarios (Ketelaar-de Lauwere et al., 1998), further supporting results from the present study. It is important to acknowledge, however, that cows in pasture-based, single-box AMS can be milked successfully with no feed reward in the AMS unit (Jago et al., 2007), despite the known positive effects of feeding on voluntary cow traffic. 
In the present study, less than $0.5 \mathrm{~kg}$ of concentrate was used to increase cow traffic through the premilking yard, supporting previous studies that reported the potential for small quantities of feed to successfully act as an incentive for milking. In single-box AMS, a comparable MF was achieved when cows were offered different quantities of concentrate (1.2 or $7 \mathrm{~kg} /$ cow per day) at milking (Halachmi et al., 2005), and analogous visiting patterns (visits per hour to the AMS) were reported for cows fed a small or large quantity (3 or 8 $\mathrm{kg}$ ) of concentrate per day in the milking robot (Bach et al., 2007). Providing cows with the concept of a reward, rather than a reward of large quantity, may offer producers currently unable to feed cows at milking in this system an option to encourage traffic without the need to deliver large quantities of feed.

It could be expected that the size of a cow affects her ability to traffic around the farm system, particularly at the dairy, where social interactions may be more prevalent due to the confined space, with social dominance reported to affect cow movement within an indoor AMS (Ketelaar-de Lauwere et al., 1996). Interestingly, however, results in the present study indicated that heifers spend the least amount of time voluntarily waiting in the premilking yard (greatest hazard of exiting the premilking yard) than all other cows. Jago and Kerrisk (2011) reported that heifers were capable of adapting rapidly to AMS in a pasture-based system, and heifers have been shown to visit the AMS more frequently and return to the AMS more rapidly than multiparous cows, regardless of routing treatment (Ketelaar-de Lauwere et al., 2000a). Therefore, despite heifers generally being smaller in size than multiparous cows, cow size (whether due to age or breed) does not appear to have a large influence on a cow's ability to successfully traffic within an AMS. Measurements of size were not performed in the present study and, therefore, the effect of size cannot be determined; however, it is clear that further research is necessary to fully understand the effects of size and breed on voluntary cow traffic in AMS, particularly at the dairy.

High-yielding cows were observed to traffic more rapidly through the premilking yard in the present study. This was not unexpected, as increases in milk production are commonly related to increases in nutrient intake, particularly energy, to support production (Kolver and Muller, 1998; Bargo et al., 2002). Therefore, it is possible that the stronger appetite (driven by higher nutrient demand) of high-yielding cows leads to a greater motivation to traffic voluntarily around the system in search of feed, as seen through faster traffic. However, it is not clear from the present study whether the reverse cause/effect (i.e., that a greater level of traffic drives higher production through more frequent access to high-quality feed) could also explain the results observed. As such, a need exists to increase understanding of this cause/effect as well as the financial and production impacts for farmers before decisions on herd structure and composition are made.

Interestingly, early-lactation cows had a lower hazard of exiting the yard and, therefore, spent a longer time waiting before milking than cows later in lactation despite producing the highest average yield. It has been reported that early-lactation cows (average 29 DIM) in a New Zealand pasture-based AMS took less time to transit along laneways and through the premilking yard, and had shorter MI than cows in late lactation (average $266 \mathrm{DIM}$ ) when animals had at least $90 \mathrm{~d}$ prior experience in the system (Jago et al., 2006). In contrast, it was reported that early-lactation cows ( $<100$ DIM) spent the longest time in the premilking area, despite having the shortest MI, when offered varying numbers of pasture allocations each day (Lyons et al., 2013a). In the present study, it is possible that late-lactation cows had more experience (albeit intermittent) milking on the RR than early-lactation cows before the study commenced. However, contrasting reports in the literature suggest that further work is necessary to more fully understand the relationship between DIM and voluntary traffic at the dairy.

A reduction in the time cows spend in the premilking yard may increase the daily yield harvested per cow, with daily yield being higher when feed was offered in the present study. This difference may have been caused by an increase in MF and an associated decrease in MI, rather than as a response to cows being offered additional feed; increases in MF have previously been shown to increase yield (Erdman and Varner, 1995; Wagner-Storch and Palmer, 2003). However, increasing MF in AMS will not always result in increased milk yield, as yield is also related to age, genetics, physiology, and nutrient intake. Cow welfare may also benefit from cows spending a shorter time in the dairy. When offered the choice between being indoors or at pasture in an AMS, cows preferred to be at pasture when ambient temperatures were favorable, and showed a preference for lying down at pasture (Ketelaar-de Lauwere and Ipema, 2000). Furthermore, hard surfaces such as concrete have been named as environmental risk factors for lameness in a review of the environmental risk factors for claw horn lesions (Cook et al., 2004). Therefore, management strategies that can reduce voluntary waiting time may positively affect not only system performance (yield per cow, as well as milkings performed by the system per day), but also aspects of cow welfare.

It was apparent that when queue length exceeded approximately 20 cows (referred to forthwith as the threshold length, where 20 cows is specific to the cur- 
rent operation), the addition of cows to the yard had less of a negative effect on the hazard of exiting than the addition of cows before reaching the threshold length. Cows are gregarious animals and it has been reported that cows return to the AMS milking barn from pasture in groups (Ketelaar-de Lauwere et al., 2000b), and in up to $90 \%$ of cases, it has been observed that cows leaving the barn were not alone, but left in groups of 2 or more animals (Ketelaar-de Lauwere et al., 1999). Therefore, management practices attempting to control queue length should consider not only the association between robot capacity and milking frequency, often attributed to queue length, but also the natural behavior of cattle.

Attempts to reduce waiting times would likely be most efficient when targeting queue lengths shorter than the threshold length; however, queue length was below the threshold length in this study less than $30 \%$ of the time when cows were offered feed, and only $5 \%$ when no feed was on offer. This difference between treatments not only highlights the positive effects of feed on cow traffic in this study, but also the magnitude of the challenge of minimizing queue length to below the desired threshold length. In a simulation of premilking queuing it was reported that limiting return milkings until more than $80 \%$ of the entire herd had been milked shortened queue length by $1 \mathrm{~h}$ in a barn system through sending cows back to their previous location (Halachmi, 2009). Considering the long distances between the paddock (feed and rest area) and the AMS unit and reduced traffic common in pasture-based systems compared with indoor-housed cows (Davis et al., 2005; Jago and Burke, 2010), it may be difficult to successfully implement such a strategy in an attempt to limit queue length in pasture-based systems due to a limited ability to reject cows for milking based on the milkings of the herd. However, an approach that may be more suitable for pasture-based systems could be the development of an appealing parking area in close vicinity to the dairy, or a priority drafting strategy. With priority drafting, cows that are over an MI threshold and deemed a high priority could be drafted directly to the robotic unit, bypassing the main queue. This strategy, in combination with the provision of a feed reward, could offer a potential solution for minimizing queue length to below the threshold length in a pasture-based RR and, thus, reduce waiting time, with the greatest potential impact being during periods of high traffic.

\section{CONCLUSIONS}

Offering concentrate pellets as a reward upon entry onto the milking platform of a pasture-based $\mathrm{RR}$ reduced the time cows spent in the premilking yard compared with when feed was not offered in a herd accustomed to receiving feed at milking. Lactation number, daily milk yield, and DIM all significantly affected waiting times, with heifers, cows in late lactation, and highyielding cows most likely to exit the premilking yard sooner (spent the shortest time waiting before milking). Once the threshold length (20 cows, in this case) was reached, the effect of an additional cow entering the premilking yard was reduced compared with the effect on the hazard before reaching the threshold. Management strategies to reduce prolonged time spent in the premilking yard should focus on minimizing queue length to below the threshold length and incorporate feed as an incentive to increase cow movement through the yard. Further work is required to recognize factors that predispose cows to prolonged waiting times as well as to develop management practices to further reduce waiting times and determine strategies to identify and target cows most likely to spend a prolonged time at the dairy.

\section{ACKNOWLEDGMENTS}

This research was carried out at the FutureDairy AMS research farm (Elizabeth Macarthur Agricultural Institute, New South Wales Department of Primary Industries, Camden, New South Wales, Australia). The authors thank the Dairy Research Foundation (Camden, New South Wales, Australia) for its support of the Dairy Science Group. We also acknowledge the research and technical assistance and contributions from the $\mathrm{Fu}$ tureDairy team and Mikael Karttunen (DeLaval International AB, Tumba, Sweden) for his technical support with the RR. This work was funded by the investors of the FutureDairy project, Dairy Australia (Southbank, Victoria, Australia), New South Wales Department of Primary Industries, DeLaval International $\mathrm{AB}$, and The University of Sydney (Camden, New South Wales, Australia).

\section{REFERENCES}

Bach, A., C. Iglesias, S. Calsamiglia, and M. Devant. 2007. Effect of amount of concentrate offered in automatic milking systems on milking frequency, feeding behavior, and milk production of dairy cattle consuming high amounts of corn silage. J. Dairy Sci. 90:5049-5055.

Bargo, F., L. D. Muller, J. E. Delahoy, and T. W. Cassidy. 2002. Performance of high producing dairy cows with three different feeding systems combining pasture and total mixed rations. J. Dairy Sci. 85:2948-2963.

Bijl, R., S. R. Kooistra, and H. Hogeveen. 2007. The profitability of automatic milking on Dutch dairy farms. J. Dairy Sci. 90:239-248.

Blanckenhorn, W. U., and T. Caraco. 1992. Social subordinance and a resource queue. Am. Nat. 139:442-449.

Cook, N. B., K. V. Nordlund, and G. R. Oetzel. 2004. Environmental influences of claw horn lesions associated with laminitis and subacute ruminal acidosis in dairy cows. J. Dairy Sci. 87(E. Suppl.):E36-E46. 
Davis, K. L., J. G. Jago, R. Wieliczko, P. J. A. Copeman, K. Bright, and M. W. Woolford. 2005. Factors influencing milk harvesting efficiency in an automatic milking system. Proc. N.Z. Soc. Anim. Prod. 65:271-275.

de Koning, K., and J. Rodenburg. 2004. Automatic milking: State of the art in Europe and North America. Pages 27-37 in Proc. Automatic Milking: A Better Understanding. Wageningen Academic Publishers, Lelystad, the Netherlands.

Erdman, R. A., and M. Varner. 1995. Fixed yield responses to increased milking frequency. J. Dairy Sci. 78:1199-1203.

Halachmi, I. 2009. Simulating the hierarchical order and cow queue length in an automatic milking system. Biosystems Eng. 102:453460.

Halachmi, I., S. Ofir, and J. Miron. 2005. Comparing two concentrate allowances in an automatic milking system. Anim. Sci. 80:339343.

Hosmer, D. W., S. Lemeshow, and S. May. 2008. Applied Survival Analysis: Regression Modelling of Time to Event Data. 2nd ed. Wiley, Hoboken, NJ.

Jago, J., and J. Burke. 2010. An evaluation of two pastoral dairy production systems using automatic milking technology. Proc. N.Z. Grassl. Assoc. 72:109-116.

Jago, J., P. Copeman, K. Bright, D. McLean, I. Ohnstad, and M. Woolford. 2002. An innovative farm system combining automated milking with grazing. Proc. N.Z. Soc. Anim. Prod. 62:115-119.

Jago, J., A. Jackson, K. Davis, R. Wieliczko, P. Copeman, I. Ohnstad, R. Claycomb, and M. Woolford. 2004. Is automatic milking possible with a $100 \%$ pasture diet? Page 307 in Proc. Automatic Milking: A Better Understanding. Wageningen Academic Publishers, Lelystad, the Netherlands.

Jago, J., A. Jackson, and M. Woolford. 2003. Dominance effects on the time budget and milking behaviour of cows managed on pasture and milked in an automated milking system. Proc. N.Z. Soc. Anim. Prod. 63:120-123.

Jago, J., and K. Kerrisk. 2011. Training methods for introducing cows to a pasture-based automatic milking system. Appl. Anim. Behav. Sci. 131:79-85

Jago, J. G., K. L. Davis, P. J. Copeman, I. Ohnstad, and M. M. Woolford. 2007. Supplementary feeding at milking and minimum milking interval effects on cow traffic and milking performance in a pasture-based automatic milking system. J. Dairy Res. 74:492499

Jago, J. G., K. L. Davis, and M. W. Woolford. 2006. Stage of lactation affects the milking performance and behaviour of cows in a pasture-based automated milking system. Proc. N.Z. Soc. Anim. Prod. 66:258-262.

Kerrisk, K. 2009. Management Guidelines for Pasture-Based AMS Farms 2010. Dairy Australia, Southbank, Victoria, Australia.

Ketelaar-de Lauwere, C. C., S. Devir, and J. H. M. Metz. 1996. The influence of social hierarchy on the time budget of cows and their visits to an automatic milking system. Appl. Anim. Behav. Sci. 49:199-211.

Ketelaar-de Lauwere, C. C., M. M. W. B. Hendriks, J. H. M. Metz, and W. G. P. Schouten. 1998. Behaviour of dairy cows under free or forced cow traffic in a simulated automatic milking system environment. Appl. Anim. Behav. Sci. 56:13-28.

Ketelaar-de Lauwere, C. C., M. M. W. B. Hendriks, J. Zondag, A. H. Ipema, J. H. M. Metz, and J. P. T. M. Noordhuizen. 2000a. Influence of routing treatments on cows' visits to an automatic milking system, their time budget and other behaviour. Acta Agric. Scand. A Anim. Sci. 50:174-183.

Ketelaar-de Lauwere, C. C., and A. H. Ipema. 2000. Cow behaviour and welfare if grazing is combined with voluntary automatic milking. Pages 289-296 in Proc. Robotic Milking. Wageningen Academic Publishers, Wageningen, the Netherlands.
Ketelaar-de Lauwere, C. C., A. H. Ipema, C. Lokhorst, J. H. M. Metz, J. P. T. M. Noordhuizen, W. G. P. Schouten, and A. C. Smits. 2000b. Effect of sward height and distance between pasture and barn on cows' visits to an automatic milking system and other behaviour. Livest. Prod. Sci. 65:131-142.

Ketelaar-de Lauwere, C. C., A. H. Ipema, E. N. J. van Ouwerkerk, M. M. W. B. Hendriks, J. H. M. Metz, J. P. T. M. Noordhuizen, and W. G. P. Schouten. 1999. Voluntary automatic milking in combination with grazing of dairy cows: Milking frequency and effects on behaviour. Appl. Anim. Behav. Sci. 64:91-109.

Kokko, H., and R. A. Johnstone. 1999. Social queuing in animal societies: A dynamic model of reproductive skew. Proc. R. Soc. Lond. Ser. B Biol. Sci. 266:571-578.

Kolbach, R., K. L. Kerrisk, S. C. García, and N. K. Dhand. 2012 Attachment accuracy of a novel prototype robotic rotary and investigation of two management strategies for incomplete milked quarters. Comput. Electron. Agric. 88:120-124.

Kolbach, R., K. L. Kerrisk, S. C. Garcia, and N. K. Dhand. 2013. Effects of bail activation sequence and feed availability on cow traffic and milk harvesting capacity in a robotic rotary dairy. J. Dairy Sci. 96:2137-2146.

Kolver, E. S., and L. D. Muller. 1998. Performance and nutrient intake of high producing Holstein cows consuming pasture or a total mixed ration. J. Dairy Sci. 81:1403-1411.

Lexer, D., K. Hagen, R. Palme, J. Troxler, and S. Waiblinger. 2009 Time budgets and adrenocortical activity of cows milked in a robot or a milking parlour: Interrelationships and influence of social rank. Anim. Welf. 18:73-80.

Lyons, N. A., K. L. Kerrisk, and S. C. Garcia. 2013a. Comparison of 2 systems of pasture allocation on milking intervals and total daily milk yield of dairy cows in a pasture-based automatic milking system. J. Dairy Sci. 96:4494-4504.

Lyons, N. A., K. L. Kerrisk, and S. C. Garcia. 2013b. Effect of preversus postmilking supplementation on traffic and performance of cows milked in a pasture-based automatic milking system. J. Dairy Sci. 96:4397-4405.

Mathijs, E. 2004. Socio-economic aspects of automatic milking. Pages 46-55 in Proc. Automatic Milking: A Better Understanding. Wageningen Academic Publishers, Lelystad, the Netherlands.

Melin, M., G. G. N. Hermans, G. Pettersson, and H. Wiktorsson. 2006 Cow traffic in relation to social rank and motivation of cows in an automatic milking system with control gates and an open waiting area. Appl. Anim. Behav. Sci. 96:201-214.

Prescott, N. B., T. T. Mottram, and A. J. F. Webster. 1998a. Effect of food type and location on the attendance to an automatic milking system by dairy cows and the effect of feeding during milking on their behaviour and milking characteristics. Anim. Sci. $67: 183-193$.

Prescott, N. B., T. T. Mottram, and A. J. F. Webster. 1998b. Relative motivations of dairy cows to be milked or fed in a Y-maze and an automatic milking system. Appl. Anim. Behav. Sci. 57:23-33.

R Core Team. 2013. R: A language and environment for statistical computing. R Foundation for Statistical Computing, Vienna, Austria. Accessed Sep. 30, 2013. http://www.R-project.org/.

Rossing, W., P. H. Hogewerf, A. H. Ipema, C. C. Ketelaar-de Lauwere, and C. J. A. M. De Koning. 1997. Robotic milking in dairy farming. Neth. J. Agric. Sci. 45:15-31.

Rotz, C. A. 2003. Whole farm impacts of automatic milking systems. Pages 355-365 in Advances in Dairy Technology. Vol. 15. J. Kennelly, ed. University Alberta, Dept. Agric., Food and Nutr. Sci., Edmonton, AB, Canada.

Wagner-Storch, A. M., and R. W. Palmer. 2003. Feeding behavior, milking behavior, and milk yields of cows milked in a parlor versus an automatic milking system. J. Dairy Sci. 86:1494-1502. 